\title{
Implementation of science and technology policies and plans
}

The world over, in particular the developed countries, have based their development policies and strategies on science, technology and innovation. Sri Lanka too recognised the importance of science and technology (S\&T) based strategies for the socio-economic development of the country.

It was as far as back as in 1978 that the first policy statement on S\&T for the country was developed. Thirteen years later in 1991, a presidential task force was mandated the development of an expanded S\&T policy. This was followed by the S\&T Development Act being passed by the Parliament in 1994. As provided for in this Act, a National Commission on Science and Technology (NASTEC) was appointed in 1998 with the powers to function as a policy advisory body on S\&T.

This Commission developed a complete and comprehensive National Science and Technology Policy (NSTP), which the government approved in 2009. This policy detailed the mechanism to achieve what was laid out in the policy. Following this exercise, NASTEC worked on a five year $(2011$ - 2016) integrated institutional action plan for implementing the NSTP, developed with the collaboration of the scientific institutions coming under the relevant ministries of the government. This collaboration was necessary since a large number of S\&T institutions were under the purview of different ministries other than the ministry in charge of S\&T. However, this action plan did not come into fruition due to reasons beyond the control of NASTEC.

In the meantime, the Ministry of Technology and Research developed a five year $(2010$ - 2015) Science, Technology and Innovation Strategy (STIS), which presented a rationalised and prioritised course of action based on the NSTP. This strategy was approved by the Cabinet of Ministers in 2011. A new organisation called the Coordinating Secretariat for Science, Technology and Innovation (COSTI) was established in 2013 to coordinate, monitor the progress and implement the strategy. With this end in view, COSTI developed a framework to take forward national science, technology and innovation activities.

In March 2016, the Ministry of Technology and Research developed a National Research and Development Investment Framework with the objective of aligning the S\&T activities with the country's development agenda.

Currently, the National Science Foundation (NSF) is in the process of organising a 'Research Summit' to be held in July 2016 with the aim of empowering research and innovation and to decide on the general directions and specific projects in the areas of Food and Agriculture, Energy and Environment, and Health. It is also envisaged that the outcomes will harness scientific research for socio-economic benefits by bridging the gap of the value chain.

All these policies, plans and frameworks have been developed often by the same scientists, technologists, administrators and development planners. They have very correctly identified the research and development directions important for the country. Therefore as expected there are many more similarities than differences in these documents, which have even indicated the general directions and specific interventions as well as research projects the researchers should consider when deciding on what areas they should work in if the work is to benefit the country.

Even with such relevant well-thought-out plans, interventions and projects that have been identified, their implementation has not proceeded satisfactorily. Therefore the answer to the question as to why the implementation of these plans have been problematic over the years must be given very serious thought by all stakeholders, in particular the scientists, technologists, administrators, development planners and of course the politicians in charge. The answers should be found sooner than later if S\&T is to contribute to the development of the country. 
The answers must also be found by these same stakeholders who were responsible for the plans. There is no easy answer to this problem, which has resulted due to many diverse reasons. The main responsibility of implementation of the policies and plans lies with the ministry in charge of S\&T. This has to be carried out with the collaboration of the other relevant ministries. Coordination of the research efforts by all relevant ministries is no doubt a most difficult task since each of these ministries also have their own priorities with respect to their research needs. It is realising this situation that both the NSTP and the STIS proposed the establishment of an inter-ministerial coordinating committees chaired by the head of state. If these committees were appointed and functioned as expected, we would not have had the problem of nonimplementation of the S\&T policies and plans.

Even without the inter-ministerial coordinating committees, the research to be undertaken by the scientists and technologists of the various ministries could have been aligned with the plans in the NSTP and STIS as well as the country's development agenda. After all, it is the same scientists and technologists who contributed to the development of the NSTP and STIP. The question is why did it not happen? It appears that instead of following the logical path of implementing the policies and plans already in place, there has been a tendency to develop new plans. This has contributed to the non-implementation of the previous plans. It is not too late even now to review all existing policies and plans along with the new plans and integrate and align them with the government's current development agenda, with a concerted effort to get the integrated plan implemented without delay. Based on this, the science administrators of the funding organisations can decide on what research to be funded.

Of all the stakeholders, the research scientists and technologists have to play an all important role by deciding and conducting the type of research aligned with the government's development agenda. This is not to say that researchers should not conduct studies that adds to the knowledge base of the country and the world. Scientists and Technologists, however, should bear in mind and work towards the enhancement of a knowledge economy relevant to our country.

Nalini Ratnasiri 